COSTING:Journal of Economic, Business and Accounting

Volume 2 Nomor 2, Juni 2019

e-ISSN : 2597-5234

https://doi.org/10.31539/costing.v2i2.565

\title{
ANALISIS PENGARUH SOSIALISASI PAJAK, SANKSI PAJAK DAN KEPATUHAN WAJIB PAJAK TERHADAP PENERIMAAN PAJAK PADA KANTOR PELAYANAN PAJAK MADYA MEDAN
}

\author{
THE EFFECT OF SOCIALIZATION, SANCTIONS AND TAX PAYER \\ OBIDIENCE ON TAX RECEIVER AT TAX SERVICE OFFICES IN MEDAN
}

\author{
Benny Rojeston Marnaek Nainggolan ${ }^{1}$, Sakaria Jonathan Putra Pinem ${ }^{2}$ \\ Fakultas Ekonomi, Universitas Prima Indonesia, Medan ${ }^{1,2}$. \\ benny.bppk@gmail.com ${ }^{1}$
}

Submit, 26-02-2019 Accepted,03-04-2019 Publish, 20-04-2019

\begin{abstract}
Tax revenue is the largest revenue in the State Budget (APBN) in the last decade. This study aims to determine the effect of Service Quality, Knowledge of Taxes, Tax Examination, Tax Counseling and Tax Sanctions on Taxpayer Compliance at Medan Middle Tax Office. This study applies certain criteria in determining samples which are often referred to as Saturated Samples. This study obtained a sample of 122 questionnaires, 30 were used for validity test and 92 for classic assumption test using SPSS test equipment. The data analysis used is multiple linear analysis and hypothesis testing. The results of the analysis obtained are Tax Dissemination and Compliance does not affect the Tax Revenue. Tax Sanctions have an influence on Tax Receipts.
\end{abstract}

Keywords: Socialization, Tax Sanctions, Taxpayer Compliance, Tax Revenue

\begin{abstract}
ABSTRAK
Penerimaan pajak merupakan penerimaan terbesar dalam Anggaran Pendapatan Belanja Negara (APBN) dalam dekade terakhir. Penelitian ini bertujuan untuk mengetahui pengaruh Kualitas Pelayanan, Pengetahuan Pajak, Pemeriksaan Pajak, Penyuluhan Pajak dan Sanksi Pajak terhadap Kepatuhan Wajib Pajak pada Kantor Pelayanan Pajak Madya Medan. Penelitian ini menerapkan kriteria tertentu dalam menentukan sampel yang sering disebut dengan Sampel Jenuh. Penelitian ini mendapatkan jumlah sampel sebanyak 122 Kuesioner, sebanyak 30 digunakan untuk uji validitas dan 92 untuk uji asumsi klasik dengan menggunakan alat uji SPSS. Data analisa yang digunakan adalah analisis linear berganda dan uji hipotesis. Hasil analisis yang diperoleh adalah Sosialisasi dan Kepatuhan Wajib Pajak tidak berpengaruh terhadap Penerimaan Pajak. Sanksi Pajak memiliki pengaruh terhadap Penerimaan Pajak.
\end{abstract}

Kata Kunci : Sosialisasi, Sanksi Pajak, Kepatuhan Wajib Pajak, Penerimaan Pajak

\section{PENDAHULUAN}

Penerimaan pajak merupakan penerimaan terbesar dalam Anggaran Pendapatan Belanja Negara (APBN) dalam dekade terakhir. Peningkatan penerimaan pajak dari tahun ke tahun tidak lepas dari kebutuhan belanja pemerintah yang setiap tahunnya 
meningkat. Dalam kenyataannya setiap tahun penerimaan pajak tidak mencapai target yang ditetapkan. Pada tahun 2016 total penerimaan pajak mencapai Rp1.105 triliun atau sebesar 81,54 persen dari target penerimaan pajak di APBN sebesar Rp1.355 triliun, tahun 2017 penerimaan pajak mencapai Rp1.339 triliun atau sebesar 91 persen dari target penerimaan sebesar Rp1.459 triliun.

Untuk mencapai target penerimaan tersebut pemerintah telah melakukan beberapa cara agar para wajib pajak mau dan patuh terhadap kewajiban perpajakannya. Salah satu cara pemerintah dan dianggap berhasil adalah program tax amnesty. Selain program tax amnesty masih ada lagi beberapa faktor yang akan meningkatkan penerimaan perpajakan, secara khusus kerelaan wajib pajak untuk memenuhi kewajibannya tanpa harus dilakukan law enforcement terhadap wajib pajak. Faktor tersebut adalah faktor sosialisasi perpajakan, sanksi pajak dan tingkat kepatuhan wajib pajak.

Sosialisasi perpajakan sangat penting bagi wajib pajak untuk mengetahui kewajiban perpajakannya, mengetahui aturan-aturan yang baru dan mengetahui sanksi atau denda yang berlaku bila mereka tidak memenuhi kewajiban perpajakannya. Sosialisasi juga merupakan cara yang dilakukan oleh pihak fiskus untuk mengedukasi wajib pajak serta masyarakat secara umum. Dalam program tax amnesty kemarin karena sosialisasinya sangat masif maka dampaknya masyarakat umum dan wajib pajak jadi semakin mengetahui pentingnya tax amnesty tersebut.

Selain sosialisasi perpajakan, hal terpenting lainnya untuk meningkatkan penerimaan perpajakan adalah sanksi pajak. Dengan menerapkan sanksi pajak yang tegas maka akan membuat wajib pajak akan melakukan kewajiban perpajakannya dengan tepat waktu dan tepat jumlah karena ada sanksi yang akan menunggu mereka bila mereka tidak melaksanakan kewajibannya dengan baik. Sanksi pajak memberikan pengaruh terhadap ketaatan wajib pajak dalam pelaksanaan kewajiban perpajakannya.

Kepatuhan wajib pajak dapat dikatakan tindakan wajib pajak dalam pemenuhan kewajiban perpajakan sesuai dengan ketentuan peraturan perundang-undangan dan peraturan pelaksanan perpajakan yang berlaku dalam suatu negara. Penerimaan pajak adalah penerimaan yang di terima oleh pemerintah dari sektor pajak. Tujuan yang paling dominan dalam penerimaan pajak baik aspek domestik maupun internasional adalah untuk memenuhi pengeluaran pemerintah. Vergina, (2013) dalam Yahya (2016).

Riyanti (2013) menyatakan bahwa sosialisasi perpajakan merupakan suatu upaya dari Direktorat Jenderal Pajak untuk memberikan pengertian, informasi dan pembinaan kepada masyarakat pada umumnya dan Wajib Pajak (WP) pada khususnya mengenai segala sesuatu yang berhubungan dengan perpajakan dan perundangundangan.

Menurut Mardiasmo (2016) sanksi perpajakan merupakan jaminan bahwa ketentuan peraturan perundangundangan perpajakan (norma perpajakan) akan dituruti atau ditaati atau dipatuhi, atau bisa dengan kata lain sanksi perpajakan merupakan alat pencegah (preventif) agar Wajib Pajak tidak melanggar norma perpajakan. Menurut Safri Nurmantu dalam Rahayu (2011) pengertian Kepatuhan WP didefinisikan sebagai suatu keadaan dimana WP dapat memenuhi semua 
kewajiban perpajakannya dan melaksanakan hak perpajakannya.

Berdasarkan kajian literatur serta penelitian terdahulu, maka rumusan hipotesis penelitian ini adalah:

H1 : Sosialisasi pajak berpengaruh positif dan signifikan terhadap penerimaan pajak

H2 : Sanksi pajak berpengaruh positif dan signifikan terhadap penerimaan pajak

H3 : Kepatuhan wajib pajak berpengaruh positif dan signifikan terhadap penerimaan pajak

\section{METODE PENELITIAN}

Data yang digunakan dalam penelitian ini adalah data primer yang dikumpulkan melalui penyebaran kuesioner. Jenis data yang digunakan dalam penelitian ini adalah data primer dan sekunder. Penelitian ini menggunakan data kuantitatif yakni berupa respon tertulis dari responden berkaitan dengan butir-butir pertanyaan atau pernyataan yang dikolaborasi dari masing-masing indikator pada setiap variabel.

$$
\text { Populasi ialah daerah }
$$
generalisasi yang terdiri atas obyek/ subyek yang memilki kuantitas juga karakteristik tertentu yang dibuat oleh peneliti untuk selanjutnya ambil kesimpulannya (Sugiyono, 2008).

Sampel adalah bagian dari jumlah dan karakteristik yang dimiliki oleh populasi. Bila populasi besar, dan peneliti tidak mungkin meneliti seluruh dari populasi tersebut, maka peneliti dapat menggunakan sampel yang diambil dari populasi tersebut. Sugiyono (2016). Dalam penentuan sampel yang diambil dari populasi yang ada, maka di pakai rumus slovin (Nugroho, 2006)

$$
n=\frac{N}{\left(1+N e^{2}\right)}
$$

Keterangan:

$\mathrm{n} \quad=$ ukuran sampel

$\mathrm{N}=$ ukuran populasi

e $=$ kelonggaran, ketidaktelitian

dan kesalahan pengambilan sampel yang ditoleransi $10 \%$.

Jumlah populasi dalam penelitian ini adalah sebanyak 1.197 WP Badan. dengan persentasi kelonggaran sebesar $10 \%$ atau 0,1 . Berikut adalah perhitungan untuk menentukan sampel dalam penelitian ini :

$$
n=\frac{1.197}{1+1197(0.1)^{2}}=\frac{1.197}{12,97}=92,28
$$

$$
\text { atau } 92 \text { WP Badan }
$$

Dari perhitungan diatas dapat disimpulkan bahwa jumlah sampel yang akan diteliti adalah sebanyak 92 Wajib Pajak Badan, kemudian akan ditambah 30 sampel untuk uji validitas dan reabilitas kuesioner yang akan dibagikan diluar sampel yang digunakan.

Metode penelitian yang digunakan yaitu penelitian kuantitatif dengan teknik analisasi data dalam penelitian ini menggunakan regresi linier berganda dengan bantuan program statistika SPSS. Namun sebelum dilanjutkan ke analisis regresi linear berganda, data hasil penelitian harus memenuhi syarat uji validitas, reliabilitas dan asumsi klasik.

Persamaan yang digunakan adalah:

$$
\mathbf{Y}=\alpha+\beta_{1} \mathbf{X}_{1}+\beta_{2} \mathbf{X}_{2}+\beta_{3} \mathbf{X}_{3}+\varepsilon
$$

Dimana:

$$
\begin{array}{ll}
\mathrm{Y} & =\text { Penerimaan Pajak } \\
\alpha & =\text { Konstanta } \\
\beta 123 & =\text { Koefisien Regresi } \\
\mathrm{X} 1 & =\text { Sosialisasi Pajak } \\
\mathrm{X} 2 & =\text { Sanksi Pajak } \\
\mathrm{X} 3 & =\text { Kepatuhan WP } \\
\varepsilon & =\text { error }
\end{array}
$$


HASIL DAN PEMBAHASAN

Uji Validitas

Uji validitas mempunyai arti sejauhmana akurasi suatu tes atau skala dalam menjalankan fungsinya. Pengukuran dikatakan mempunyai validitas yang tinggi apabila menghasilkan data yang secara akurat memberikan gambaran mengenai variabel yang diukur seperti dikehendaki oleh tujuan pengukuran tersebut (Azwar 2015).

\section{Uji Reliabilitas}

Uji Reliabilitas merupakan tingkat pengukuran yang bebas dari kesalahan dan oleh karenanya menghasilkan hasil yang konsisten. Dengan kata lain, reliabilitas adalah alat ukur mengindikasikan stabilitas dan konsistensi ketika alat ukur digunakan mengukur konsep (Nuryaman dan Christina, 2015).

Tabel 1. Hasil Uji Reliabilitas

\begin{tabular}{lcc}
\hline \multicolumn{1}{c}{ Variabel } & $\begin{array}{c}\text { Cronbach } \\
\text { Alpha }\end{array}$ & Keterangan \\
\hline $\begin{array}{l}\text { Sosialisasi } \\
\text { Pajak (X1) }\end{array}$ & 0,890 & Reliable \\
\hline $\begin{array}{l}\text { Sanksi } \\
\text { Pajak (X2) }\end{array}$ & 0,773 & Reliable \\
\hline $\begin{array}{l}\text { Kepatuhan } \\
\text { Wajib Pajak } \\
\text { (X3) }\end{array}$ & 0,839 & Reliable \\
\hline $\begin{array}{l}\text { Penerimaan } \\
\text { Pajak (Y) }\end{array}$ & 0,943 & Reliable \\
\hline
\end{tabular}

Sumber : Pengolahan Data

Hasil diatas menyatakan bahwa semua variabel memiliki koefisien Alpha yang cukup atau memenuhi kriteria, sehingga selanjutnya item-item pada masing-masing konsep variabel tersebut layak digunakan sebagai alat ukur.

\section{Analisis Regresi Linier Berganda}

Analisis regresi dilakukan untuk menguji hipotesis tentang pengaruh secara parsial variabel bebas terhadap variabel terikat.
Tabel 2. Analisis Regresi Linier Berganda

\begin{tabular}{llrc}
\hline No & \multicolumn{1}{c}{ Variabel } & \multicolumn{1}{c}{$\begin{array}{c}\text { Std. } \\
\text { Koef }\end{array}$} & \multicolumn{1}{c}{ Error } \\
\hline 1 & (Constant) & 10,785 & 5,163 \\
\cline { 2 - 4 } 2 & Sosialisasi pajak & 0,086 & 0,080 \\
\cline { 2 - 4 } 3 & Sanksi Pajak & 0,426 & 0,077 \\
\cline { 2 - 4 } 4 & Kepatuhan Wajib & 0,136 & 0,116 \\
& Pajak \\
Sumber : Pengolahan Data \\
Sasil persamaan yang terbentuk \\
adalah:
\end{tabular}

$\mathrm{Y}=10,785+0,086 \mathrm{X}_{1}+0,426 \mathrm{X}_{2}+$ $0,136 \mathrm{X}_{3}+\varepsilon$

Keterangan:

$\mathrm{Y} \quad=$ Penerimaan Pajak

$\mathrm{X}_{1} \quad=$ Sosialisasi Pajak

$\mathrm{X}_{2} \quad=$ Sanksi Pajak

$\mathrm{X}_{3} \quad=$ Kepatuhan WP

$\varepsilon \quad=$ error

Hasil persamaan regresi tersebut dijabarkan sebagai berikut:

1. Nilai konstanta a sebesar 10,785 artinya bahwa jika tidak terdapat variabel Sosialisasi Pajak, Sanksi Pajak, Kepatuhan Wajib Pajak $=0$ maka Penerimaan Pajak akan bernilai sebesar 10,785 satuan.

2. Variabel Sosialisasi Pajak memiliki nilai koefisien $b_{1}=0,086$ yang artinya setiap kenaikan variabel Sosialisasi Pajak sebesar 1 satuan, maka nilai pada Penerimaan Pajak akan naik 0,086 satuan dengan asumsi bahwa variabel yang lain akan tetap.

3. Variabel Sanksi Pajak memiliki nilai koefisien $b_{2}=0,426$ yang artinya setiap kenaikan variabel Sanksi Pajak sebesar 1 satuan, maka nilai pada Penerimaan Pajak akan naik 0,426 satuan dengan asumsi bahwa variabel yang lain akan tetap.

4. Variabel Kepatuhan Wajib Pajak memiliki nilai koefisien $b_{3}=0,136$ yang artinya setiap kenaikan variabel Kepatuhan Wajib Pajak 
sebesar 1 satuan, maka nilai pada Penerimaan Pajak akan naik 0,136 satuan dengan asumsi bahwa variabel yang lain akan tetap.

\section{Uji Asumsi Klasik}

\section{Uji Normalitas}

Uji normalitas bertujuan agar bisa menguji apakah dalam model regresi, variabel bebas dan variabel terikat, keduanya terdistribusikan secara normal atau tidak.

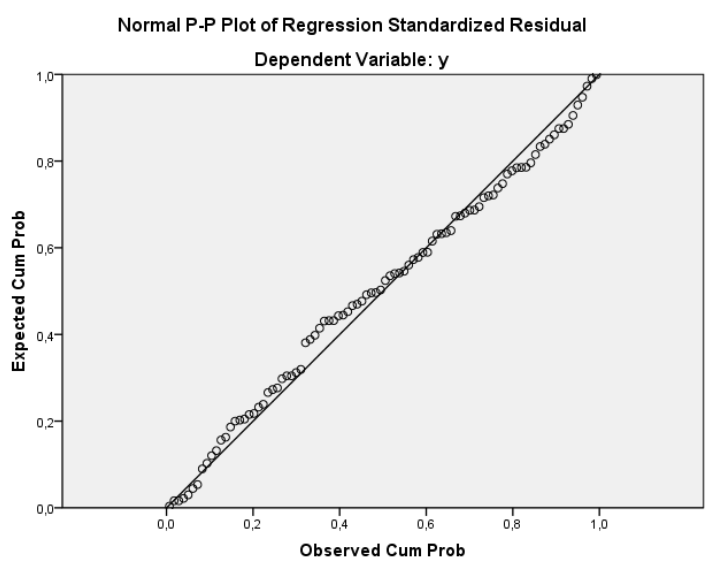

\section{Gambar 1. Hasil Uji Normalitas}

Setelah dilakukan pengujian ternyata semua data terdistribusi secara normal, sebaran data berada disekitar garis diagonal. Hal ini menunjukkan bahwa model regresi dalam penelitian ini memenuhi asumsi normalitas.

\section{Uji Multikolinearitas}

Bertujuan untuk mengetahui hubungan yang sempurna antara variabel bebas dalam model regresi.

Tabel 3. Hasil Uji Multikolinearitas

\begin{tabular}{llrl}
\hline No. Variabel & \multicolumn{2}{c}{ Collinearity } \\
& & \multicolumn{2}{c}{ Statistics } \\
\cline { 2 - 4 } & & e & VIF \\
\hline 1 & Sosialisasi Pajak &, 993 & 1,007 \\
\cline { 2 - 3 } 2 & Sanksi Pajak &, 919 & 1,088 \\
\cline { 2 - 3 } 3 & Kepatuhan Wajib &, 921 & 1,086 \\
& Pajak \\
\hline Sumber : Hasil Pengolahan Data \\
\hline \multicolumn{3}{c}{ Dari tabel diatas menunjukkan } \\
bahwa nilai VIF semua variabel bebas \\
dalam penelitian ini lebih kecil dari 10
\end{tabular}

sedangkan nilai toleransi semua variabel bebas lebih dari $10 \%$ yang berarti tidak terjadi korelasi antar variabel bebas yang nilainya dari 90\%, dengan demikian bisa disimpulkan bahwa tidak terjadi gejala multikolinearitas antar variabel bebas dalam model regresi.

\section{Uji Heterokedastisitas}

Uji heterokedastisitas dilakukan untuk mengetahui apakah dalam model regresi terjadi ketidaksamaan varians dari residual suatu pengamatan ke pengamatan lain.

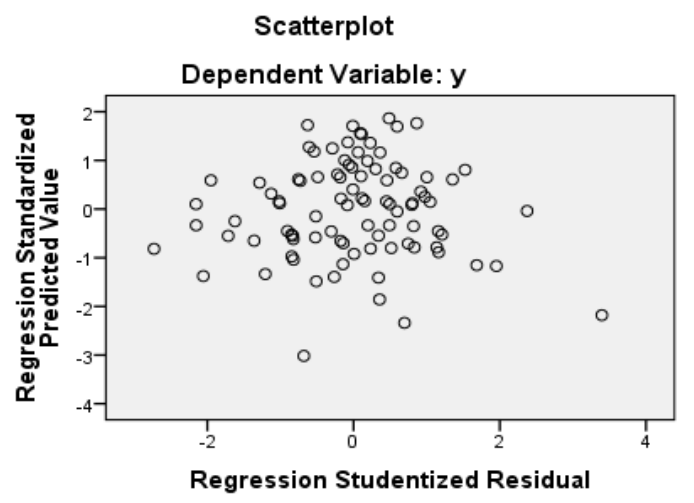

\section{Gambar 2. Hasil Uji Heterokedastisitas}

Dari hasil uji heterokedastisitas yang telah dilakukan ternyata titik-titik dapat disebut juga data menyebar secara acak, tidak membentuk suatu pola tertentu yang jelas, serta tersebar baik di atas maupun di bawah angka 0 (nol) pada sumbu Y, hal ini berarti tidak terjadi penyimpangan asumsi klasik heterokedastisitas pada model regresi yang dibuat, dengan kata lain menerima hipotesis homoskedastisitas.

\section{Uji Hipotesis \\ Uji Parsial (Uji t)}

Pengujian ini dilakukan untuk mengetahui apakah variabel independen berpengaruh terhadap variabel dependen secara signifikan secara parsial (Ghozali 2006). Pengujian dilakukan dengan melihat taraf signifikan ( $p$-value), jika taraf signifikansi yang dihasilkan dari perhitungan di bawah 0,05 maka 
hipotesis diterima, sebaliknya jika taraf signifikansi hasil hitung lebih besar dari 0,05 maka hipotesis ditolak.

\section{Tabel 4. Hasil Uji t}

\begin{tabular}{llrrc}
\hline No & Variabel & $\mathbf{T}_{\text {hitung }}$ & $\mathbf{T}_{\text {tabel }}$ & Sig \\
\hline 1 & (Constant) & 2,050 & - & 0,043 \\
\hline 2 & $\begin{array}{l}\text { Sosialisasi } \\
\text { Pajak }\end{array}$ & 1,113 & 1,661 & 0,269 \\
\hline 3 & $\begin{array}{l}\text { Sanksi } \\
\text { Pajak }\end{array}$ & 5,535 & 1,661 & 0,000 \\
\hline 4 & $\begin{array}{l}\text { Kepatuhan } \\
\text { WP }\end{array}$ & 1,167 & 1,661 & 0,246 \\
& & & \\
\hline
\end{tabular}

Sumber : Pengolahan Data

Dari hasil uji t, dapat dijelaskan sebagai berikut:

1. Nilai $t_{\text {hitung }}$ untuk variabel sosialisasi pajak $(1,113)<\mathrm{t}_{\text {tabel }}(1,661)$, dengan nilai signifikansi $0,269>0,05$ maka $\mathrm{H}_{0}$ diterima dan $\mathrm{Ha}$ ditolak yang berarti secara parsial sosialisasi pajak tidak berpengaruh terhadap penerimaan pajak pada KPP Madya Medan.

2. Nilai $t_{\text {hitung }}$ untuk variabel sanksi pajak $(5,535)>t_{\text {tabel }}(1,661)$, dengan nilai signifikansi $0,000<0,05$ maka $\mathrm{H}_{0}$ ditolak dan $\mathrm{Ha}$ diterima yang berarti secara parsial sanksi pajak berpengaruh positif dan signifikan terhadap penerimaan pajak pada KPP Madya Medan.

3. Nilai $t_{\text {hitung }}$ untuk variabel kepatuhan WP $(1,167)<t_{\text {tabel }}(1,661)$, dengan nilai signifikansi $0,246>0,05$ maka $\mathrm{H}_{0}$ diterima dan $\mathrm{Ha}$ ditolak yang berarti secara parsial kepatuhan WP tidak berpengaruh terhadap penerimaan pajak pada KPP Madya Medan.

\section{Uji Simultan (Uji F)}

Pengujian ini dilakukan untuk mengetahui pengaruh semua variabel independen yang dimasukkan ke dalam variabel model regresi secara bersamasama terhadap variabel dependen.
Tabel 5. Hasil Uji F

\begin{tabular}{lccc}
\hline \multicolumn{1}{c}{ Model } & Df & F & Sig \\
\hline Regression & 3 & 13,688 & 0,000 \\
\hline Residual & 88 \\
\hline Total & 91 \\
\hline Sumber : Pengolahan Data 2018 \\
Pada uji $F$ diperoleh hasil $\mathrm{F}_{\text {hitung }}$ & 13,688 \\
sedangkan & $\mathrm{F}_{\text {tabel }}$ & 2,71 dari hasil ini \\
diketahui $\mathrm{F}_{\text {hitung }}>\mathrm{F}_{\text {tabel }}$ dan signifikasi \\
nya $0,000<0,05$ yang berarti $\mathrm{H}_{0}$ ditolak \\
atau $\mathrm{H}_{\mathrm{a}}$ diterima yang artinya bahwa \\
variabel sosialisasi pajak, sanksi pajak \\
dan kepatuhan wajib pajak secara \\
bersama-sama berpengaruh positif dan \\
signifikan terhadap variabel penerimaan \\
pajak pada KPP Madya Medan.
\end{tabular}

\section{Uji Koefisien Determinasi $\left(\mathbf{R}^{\mathbf{2}}\right)$}

Koefisiensi determinasi $\left(\mathrm{R}^{2}\right)$ pada intinya mengukur seberapa jauh kemampuan model dalam menerangkan variasi variabel dependen. Nilai koefisien determinasi adalah antara nol dan satu. Nilai $\mathrm{R}^{2}$ yang kecil berarti kemampuan variabel-variable independen dalam menjelaskan variasi variabel dependen amat terbatas. Nilai yang mendekati satu berarti variabelvariabel independen memberikan hampir semua informasi yang dibutuhkan untuk memprediksi variasi variabel dependen (Ghozali, 2009).

Tabel 6. Hasil Koefisien Determinasi Koefisien Determinasi

Nilai $R^{2} 0,318$ yang artinya bahwa kemampuan variasi variabel Sosialisasi Pajak, Sanksi Pajak, Kepatuhan Wajib Pajak dapat menjelaskan variasi dari Penerimaan Pajak adalah sebesar 31,8\% dan sisa nya dijelaskan oleh variabel lain yang tidak di jelaskan dalam penelitian ini. 
PENUTUP

Kesimpulan

Dari hasil pembahasan dapat disimpulkan

1. Sosialisasi pajak dan kepatuhan wajib pajak tidak berpengaruh terhadap penerimaan pajak pada KPP Madya Medan.

2. Sanksi pajak berpengaruh positif dan signifikan terhadap penerimaan pajak pada KPP Madya Medan, hal ini berarti bahwa dengan ditegakkannya sanksi perpajakan akan berdampak terhadap penerimaan pajak.

3. Sosialisasi pajak, sanksi pajak dan kepatuhan wajib pajak secara bersama-sama berpengaruh positif dan signifikan terhadap penerimaan pajak pada KPP Madya Medan.

\section{Saran}

Saran yang dapat diberikan untuk peneliti selanjutnya adalah menggunakan variabel lain seperti pemeriksaan pajak, kualitas pelayanan dan serta kesadaran wajib pajak dll yang dapat mendukung penelitian ini selanjutnya serta menggunakan objek yang berbeda.

\section{DAFTAR PUSTAKA}

Mardiasmo. (2016). Perpajakan Edisi Terbaru 2016. Edisi 18, Yogyakarta: CV Andi Offset.

Yahya. (2016). Pengaruh Sosialisasi Perpajakan dan Ekstensifikasi Pajak Terhadap Penerimaan Pajak Penghasilan Orang Pribadi. Jurnal Universitas Sarjanawiyata Tamansiswa.

Riyanti, Sukmo. (2013). Pengaruh Sosialisasi Perpajakan, Kualitas Pelayanan, dan Sanksi Perpajakan Terhadap Kepatuhan Wajib Pajak Badan Tahun 2014. Jurnal Universitas Mercu Buana.
Rahayu, Dwi. (2010). Analisis Pengaruh Pemeriksaan Pajak Terhadap Kepatuhan Wajib Pajak pada Kantor Pelayanan Pajak Pratama Semarang Selatan. Semarang

Sugiyono. (2012). Metode Penelittian Bisnis. Bandung: Alfabeta.

Azwar, Saifuddin. (2015). Reliabilitas dan Validitas. Edisi 4. Yogyakarta: Pustaka Pelajar.

Ghozali, Imam. (2009). Aplikasi Analisis Muktivariate Dengan Program SPSS. Ed 4. Semarang: Badan Penerbit Universitas Diponegoro. 